\title{
Pt-Catalyzed Cyclization/1,2-Migration for the Synthesis of Indolizines, Pyrrolones, and Indolizinones
}

\author{
Cameron R. Smith, Eric M. Bunnelle, Allison J. Rhodes, and Richmond Sarpong \\ Department of Chemistry, University of California, Berkeley, California 94720
}

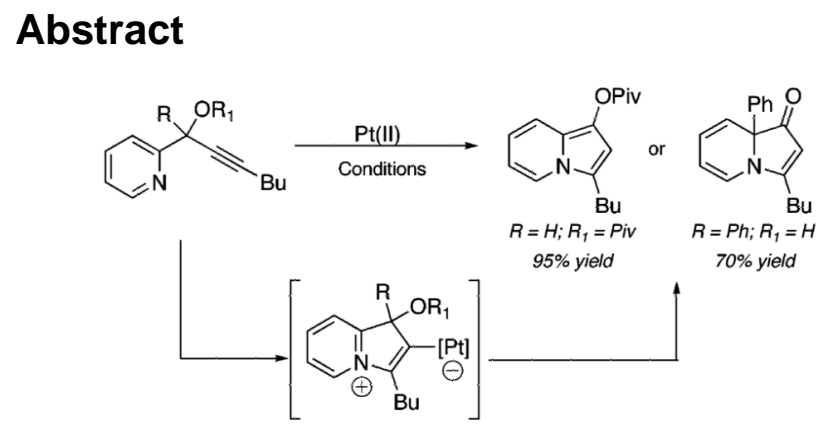

Indolizine, pyrrolone, and indolizinone heterocycles are easily accessed via the Pt(II)-catalyzed cycloisomerization or a tandem cyclization/1,2-migration of pyridine propargylic alcohols and derivatives. This method provides an efficient synthesis of highly functionalized heterocycles from readily available substrates.

The development of efficient and versatile strategies for the synthesis of heterocycles continues to be of major significance in synthetic organic chemistry. ${ }^{1}$ In this regard, transformations that employ readily available substrates to provide access to multiply functionalized heterocycles are highly desirable. In the last two decades, the pharmacological potential of indolizines and related derivatives has become well recognized. ${ }^{2}$ As a result, a variety of methods for their syntheses have emerged. ${ }^{3}$ However, there still remains a significant need for more direct methods to afford functionalized indolizine derivatives.

Previously, we reported the Pt-catalyzed cyclization of an acetate nucleophile (see 1, Scheme 1) onto an activated alkyne to achieve the formation of pentannulated products (e.g., 3), via the intermediacy of a zwitterion (2). ${ }^{4,5}$ On the basis of this precedent, we reasoned that substrates such as 4 (Scheme 2), which possess a nitrogen nucleophile, could provide a platform for metal-catalyzed cycloisomerizations to access a range of nitrogen-containing heterocycles (e.g., 6).

Optimization studies of this transformation began with propargylic ester 7a (Table 1), which was easily prepared from pyridine-2-carboxaldehyde in two steps. ${ }^{6}$ Initial attempts identified $\mathrm{PtCl}_{4}$ (entry 1) and $\mathrm{PtCl}_{2}$ (entry 2) to be suitable catalysts that provide moderate yields of the desired $\mathrm{C}-1$ substituted indolizine $8 \mathrm{a}$ at $70{ }^{\circ} \mathrm{C}{ }^{7}$

(C) 2007 American Chemical Society

*rsarpong@berkeley.edu.

Supporting Information Available: Experimental details and characterization data for all new compounds. This material is available free of charge via the Internetat http://pubs.acs.org. 
Furthermore, after a screen of various additives, we were delighted to find that the addition of $10 \mathrm{~mol} \%$ of the bulky, electron-rich phosphine ligands 2-(di-tert-butylphosphino)biphenyl $^{8}$ (9, entry 3$)$ or 2-(dicyclohexylphosphino)biphenyl (10, entry 4$)$ to the reaction mixture with $\mathrm{PtCl}_{2}$ as catalyst led to a significant increase in the yield of the indolizine product $\mathbf{8 a}$, with $\mathbf{1 0}$ proving to be superior (79\% yield). The utility of phosphine ligands in facilitating Pt(II)-catalyzed reactions involving nitrogen nucleophiles is consistent with recent observations made by Widenhoefer during studies of the hydroamination of olefins. ${ }^{9}$ Importantly, for the hydroamination reactions reported by Widenhoefer, a 1:1 ratio of $\mathrm{Pt}(\mathrm{II})$ salt to exogenous phosphine (Pt/PR $)$ was critical to success. ${ }^{10} \mathrm{We}$ reasoned that the use of bulky phosphines would dictate the formation of this critical 1:1 Pt/PR 3 complex, which led to the choice of $\mathbf{9}$ and $\mathbf{1 0}$ as additives.

Significant differences in reaction efficiency were also observed upon exposure of internal alkyne substrates (e.g., 7b) to various Pt(II)-catalyzed cycloisomerization conditions as outlined in entries 5-11. Consistent with our initial observations (entries 1-4), bulky phosphine additives provided conditions that produced higher yields of the desired indolizine product (i.e., $8 \mathbf{b}$, entries 6 and 7) as compared to $\mathrm{PtCl}_{2}$ alone (entry 5).

The effect of phosphines $\mathbf{9}$ and $\mathbf{1 0}$ on reaction efficiency was more pronounced at $40{ }^{\circ} \mathrm{C}$. At this temperature, there was no reaction with $\mathrm{PtCl}_{2}$ alone as the catalyst (entry 8), whereas with $\mathbf{9}$ and $\mathbf{1 0}$ as additives (entries 9 and 10, respectively), product formation was observed, with 9 proving to be optimal. Interestingly, indium trichloride also catalyzes the transformation of $\mathbf{7 b}$ to $\mathbf{8 b}$ (entry 11) albeit in lower overall yields. However, this catalyst was found to be ineffective in the transformation of substrates possessing terminal alkynes (e.g., 7a).

As shown in Figure 1, a range of indolizine products are easily obtained utilizing the optimized reaction conditions with either $\mathrm{Pt}(\mathrm{II})\left(5 \mathrm{~mol} \%\right.$ of $\mathrm{PtCl}_{2}, 10 \mathrm{~mol} \%$ of 2-(di-tertbutylphosphino)biphenyl (9), $0.2 \mathrm{M}$ in $\left.\mathrm{PhH}, 70{ }^{\circ} \mathrm{C}\right)$ or In-(III) $\left(5 \mathrm{~mol} \%\right.$ of $\mathrm{InCl}_{3}, 0.2 \mathrm{M}$ in $\mathrm{PhH}, 70{ }^{\circ} \mathrm{C}$ ). The pivalate protective group was found to be ideal (see 11-14), and a range of alkyl-, cycloalkyl-, aryl-, and alkenyl-substituted indolizines are readily obtained in modest to good yields. Of note, silyl protective groups may be employed as evidenced by the formation of silylated indolizine $\mathbf{1 5}$ in $57 \%$ yield. ${ }^{11}$

On the basis of these initial studies, we hypothesized that tertiary propargylic alcohol substrates such as $\mathbf{1 6}$ (Scheme 3) could provide a platform for metal-catalyzed cycloisomerizations that involve a 1,2 -shift. ${ }^{12}$

This would provide access to a range of highly substituted heterocycles. In a preliminary study, pyrrolone 19 was formed in $71 \%$ yield upon treatment of hydrazone 16 with $\mathrm{PtCl}_{2}$ (10 $\mathrm{mol} \%$ ) for $24 \mathrm{~h}$ at $100{ }^{\circ} \mathrm{C}$. Presumably, this conversion proceeds via initial formation of $\mathbf{1 7}$, which yields 18 upon proton transfer. An ensuing 1,2-shift of the ethyl group affords $19 .{ }^{13}$

Despite our initial success in transforming 16 to pyrrolone 19, our general conditions proved to be ineffective at low catalyst loadings for substrates that contain a pyridine fragment. A screen of various additives, solvents, and temperatures identified a set of optimized conditions (5 mol \% of $\mathrm{PtCl}_{2}, 10 \mathrm{~mol} \%$ of 2-(di-tert-butylphosphino)biphenyl, 0.1 equiv of $\mathrm{Cs}_{2} \mathrm{CO}_{3}, 100^{\circ} \mathrm{C}$ ), which was readily applicable to several tertiary propargylic alcohol substrates (20a-e, Table 2) to provide the corresponding indolizinones (21a-e) in modest to good yields. The addition of substoichiometric quantities of a base $\left(\mathrm{Cs}_{2} \mathrm{CO}_{3}\right)$, which may facilitate proton-transfer events prior to the 1,2-migration event, was found to be critical. ${ }^{14}$ Importantly, preliminary results indicate that the 1,2-migrations occur with high 
stereoselectivity as evidenced by the efficient transfer of chirality in the formation of enantioenriched indolizinone 21 a (97\% ee, eq 1) from 20a (99.9\% ee). ${ }^{15,16}$

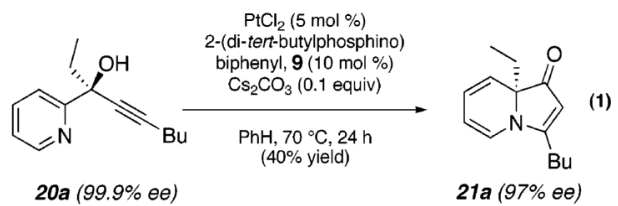

To the best of our knowledge, the work reported herein represents the first examples of this mechanistically distinct, metal-catalyzed cycloisomerization that allows access indolizines and indolizinones and for the first time highlights the significant effect of bulky electronrich phosphines on these cycloisomerization transformations. Further studies probe the mechanisms of these transformations, broaden the scope to include other examples of chirality transfer, identify conditions to shorten the reaction times are underway. Additionally, applications of these heterocycles in natural product synthesis are currently ongoing and will be reported in due course.

\section{Supplementary Material}

Refer to Web version on PubMed Central for supplementary material.

\section{Acknowledgments}

The authors would like to thank Ms. Christina Kraml (AccelaPure Corp., Frick Lab Rm Princeton University, Princeton, NJ 08544) for enantioenriched samples of 20a and Johnson Matthey for a gift of $\mathrm{PtCl}_{2}$. The authors are also grateful to UC Berkeley, Eli Lilly, and GlaxoSmithKline for generous financial support.

\section{References}

(1). For a recent general review, see: Joule JA, Mills K. Heterocyclic Chemistry (4th ed). 2000Blackwell Science LtdCambridge, MA

(2). Michael JP. Nat. Prod. Rep. 1999; 16:675.

3 (a). For recent examples, see: Kaloko J Jr. Hayford A. Org. Lett. 2005; 7:4305. [PubMed: 16146413] Kel'in AV, Sromek AW, Gevorgyan V. J. Am. Chem. Soc. 2001; 123:2074. [PubMed: 11456838] Seregin IV, Gevorgyan V. J. Am. Chem. Soc. 2006; 128:12050. [PubMed: 16967938] Marchalin S, Baumlová B, Baran P, Oulyadi H, Daïch A. J. Org. Chem. 2006; 71:9114. [PubMed: 17109537]

(4). Prasad, B. A. Bhanu; Yoshimoto, FK.; Sarpong, R. J. Am. Chem. Soc. 2005; 127:12468. [PubMed: 16144376]

(5) (a). Metallocarbenoid intermediates, generated from 2, are believed to be important in these transformations. See: Mamane V, Gress T, Krause H, Fürstner A. J. Am. Chem. Soc. 2004; 126:8654. [PubMed: 15250709] Miki K, Ohe K, Uemura S. J. Org. Chem. 2003; 68:8505. [PubMed: 14575478] Harrak Y, Biaszykowski C, Benard M, Cariou K, Manetti E, Mouriés V, Dhimane A-L, Fensterbank L, Malacria M. J. Am. Chem. Soc. 2004; 126:8656. [PubMed: 15250710]

(6). For details, see Supporting Information.

(7). Heating 7a without added catalyst at $120^{\circ} \mathrm{C}$ over $48 \mathrm{~h}$ yielded minor amounts of $\mathbf{8 a}$ (ca. $15 \%$ yield) along with significant byproducts. This points to a slow and inefficient background reaction.

(8) (a). Tomori H, Fox JM, Buchwald SL. J. Org. Chem. 2000; 65:5334. [PubMed: 10993363] (b) Fox JM, Huang X, Chieffi A, Buchwald SL. J. Am. Chem. Soc. 2000; 122:1360. 
(9) (a). Bender CF, Widenhoefer RA. J. Am. Chem. Soc. 2005; 127:1070. [PubMed: 15669824] (b) Qian H, Widenhoefer RA. Org. Lett. 2005; 7:2635. [PubMed: 15957909]

(10). Wang X, Widenhoefer RA. Organometallics. 2004; 23:1649.

(11). Previously, $\mathrm{PtCl}_{2}$ was reported to be an ineffective catalyst for the cycloisomerization that results in 15. See ref $2 c$.

(12). For an example of a-hydroxyiminium 1,2-migration, see: Fenster MDB, Patrick BO, Dake GR. Org. Lett. 2001; 3:2109. [PubMed: 11418061]

(13). For examples using cyclic a-ketols, see: Kirsch SF, Binder JT, Liébert C, Menz H. Angew. Chem., Int. Ed. 2006; 45:5878.

(14). The formation of a cesium alkoxide prior to 1,2-migration may also be important.

(15). Enantioenriched 20a was obtained via preparative chiral column chromatography of the racemate. 6

(16). Efforts to delineate whether this transformation is stereospecific and whether the loss of ee in forming enantioenriched 21 a occurs via a competing process are currently ongoing. 
<smiles>CCCCc1cc(Br)n2ccccc12</smiles><smiles>Oc1cc(C2CC2)n2ccccc12</smiles><smiles>[N+]=Nc1cc(-c2ccccc2)n2ccccc12</smiles>

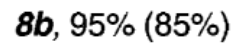

$11,80 \%(83 \%)$

$12,99 \%(92 \%)$<smiles>CCOc1cc(C2=CCCCC2)n2ccccc12</smiles><smiles>CCOc1cc(Br)n2c1ccc1ccccc12</smiles>

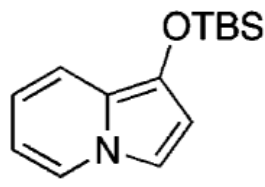

$13,79 \%(81 \%)$

$14,88 \%(83 \%)$

$15,57 \%$

Figure 1.

$\mathrm{Pt}(\mathrm{II})$ - and In(III)-catalyzed cycloisomerizations. Yields are indicated for reactions using $\mathrm{PtCl}_{2}$ and $\mathrm{InCl}_{3}$ (in parentheses). For a full description of reaction details, including the identity of propargylic ester substrates, see Supporting Information. 


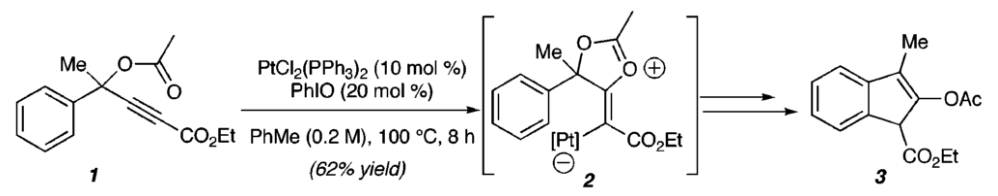

Scheme 1.

Pt(II)-Catalyzed Pentannulation 


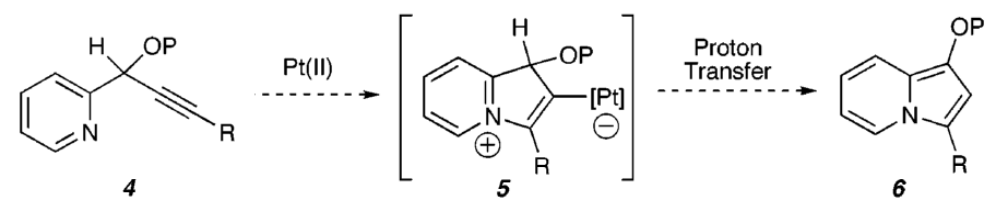

Scheme 2.

Proposed Heterocycloisomerization 

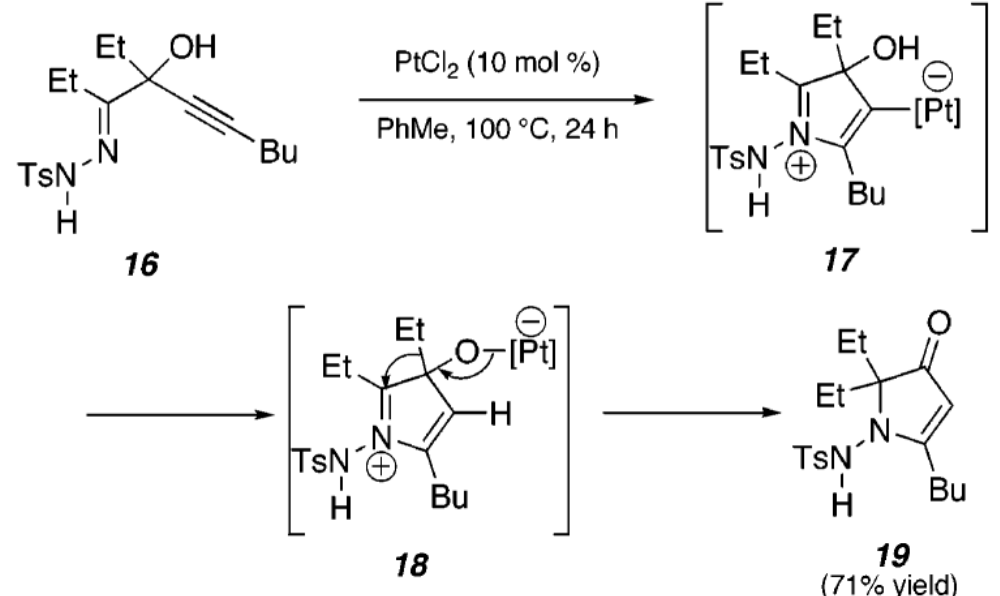

Scheme 3.

Tandem Cyclization/1,2-Migration of 16 
Table 2

Pt-Catalyzed Formation of Indolizinones
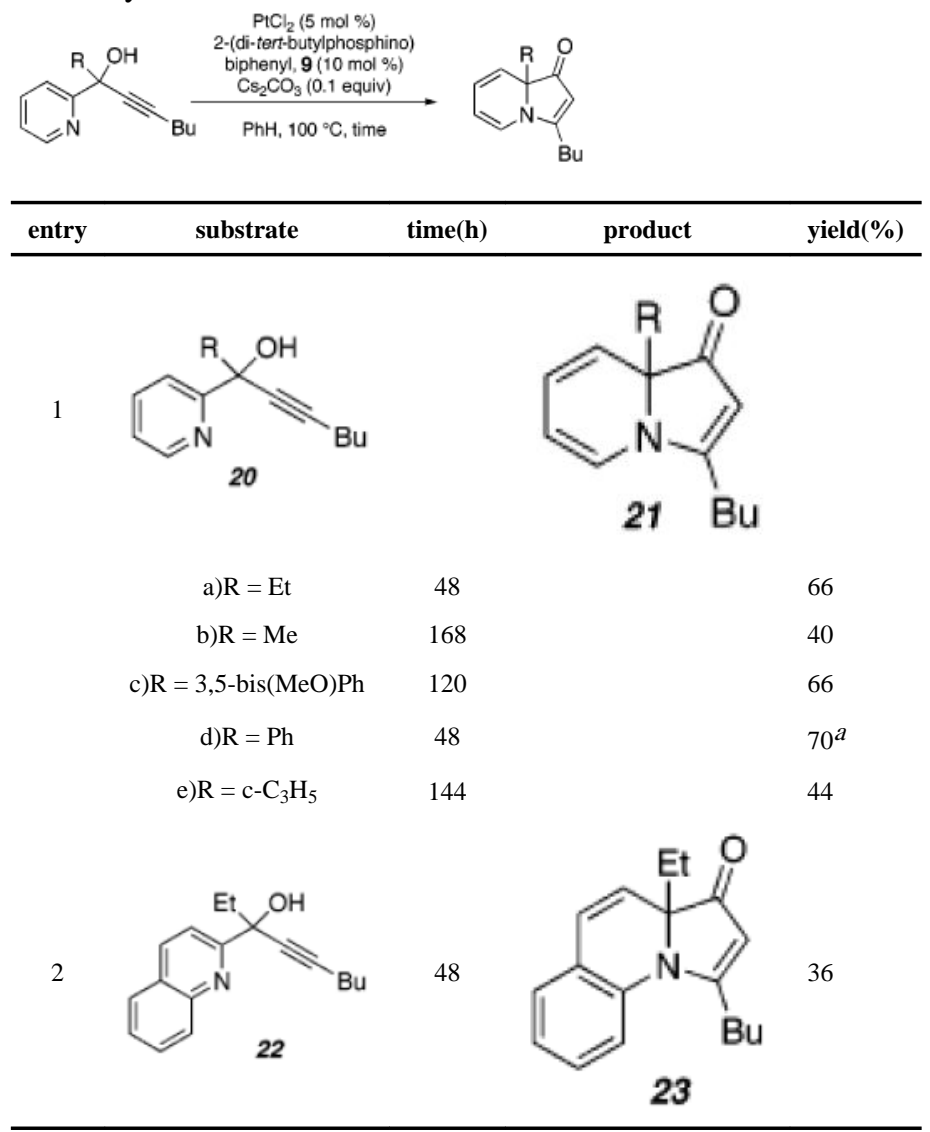

${ }^{a} \mathrm{Cs}_{2} \mathrm{CO}_{3}$ was not used as an additive. 